\title{
The Association Between Primary Open Angle Glaucoma and Clustered Components of Metabolic Syndrome
} \author{
Mohammad Montazeri ${ }^{6}$ and Hesam Hedayati ${ }^{2}$ \\ ${ }^{I}$ Department of Ophthalmology, Babol University of Medical Sciences, Babol, Iran \\ ${ }^{2}$ Department of Ophthalmology, Jundishapur University of Medical Sciences, Ahvaz, Iran \\ ${ }^{3}$ Department of Cardiology, Tehran University of Medical Sciences, Tehran, Iran \\ ${ }^{4}$ Department of Internal Medicine, Tehran University of Medical Sciences, Tehran, Iran \\ ${ }^{5}$ Department of Internal Medicine, Shiraz University of Medical Sciences, Shiraz, Iran \\ ${ }^{6}$ Young Researchers Club, Islamic Azad University, Babol Branch, Babol, Iran
}

Seyed Ahmad Rasoulinejad ${ }^{1}$, Ali Kasiri ${ }^{2}$, Mahdi Montazeri ${ }^{3}$, Negin Rashidi ${ }^{4}$, Maryam Montazeri ${ }^{*}, 5$,

\begin{abstract}
Purpose: There is conflicting evidence whether components of metabolic syndrome (MetS) increase or decrease the risk of primary open-angle glaucoma (POAG). The aim of the present study was to determine the association between metabolic syndrome and primary open-angle glaucoma.

Methods: A total of 200 participants comprising 100 controls and 100 patients with POAG documented by clinical tests and examined by an experienced ophthalmologist using standard ophthalmologic equipment were included in the study. MetS was defined and based on ATP III criteria and POAG was defined by the criteria of the International Society of Geographic and Epidemiological Ophthalmology (ISGEO). The data were entered into the SPSS software and analyzed.

Results: The prevalence of MetS in the glaucoma group was $53 \%$ in comparison to $38 \%$ in the control group ( $\mathrm{p}=0.037$ ). MetS was associated with an increased odds ratio for an IOP higher than $21 \mathrm{mmHg}$ (OR: 1.72; 95\% CI 1.03-2.79; $\mathrm{p}=0.034)$. The mean IOP was $24.91 \pm 4.29 \mathrm{mmHg}$ in the patients without MetS, and $27.23 \pm 4.81 \mathrm{mmHg}$ in those with MetS $(\mathrm{p}=0.027)$. The mean values of CCT were $603.64 \pm 63.16 \mu \mathrm{m}$ in MetS patients and 579.27 $\pm 72.87 \mu \mathrm{m}$ in controls $(\mathrm{p}=0.018)$.

Conclusion: Data showed an increased prevalence of components of metabolic syndrome in patients with glaucoma. The mechanisms underlying these associations need to be established in future studies. Our results support the recommendation that patients with metabolic syndrome undergo regular ophthalmological exams to monitor for the onset or progression of glaucoma.
\end{abstract}

Keywords: Central corneal thickness, intraocular pressure, metabolic syndrome, open-angle glaucoma.

\section{INTRODUCTION}

Primary open-angle glaucoma (POAG) is a chronic and age-related disease that is the leading cause of irreversible visual disability [1]. To eliminate avoidable blindness, the International Agency for the Prevention of Blindness (IAPB) and the World Health Organization (WHO) included glaucoma in the list of priority blinding eye diseases of the VISION 2020 initiative [2]. The OAG is usually asymptomatic till advanced stages of the disease, knowing the risk factors associated with the onset or progression of OAG will help clinicians to better identify who will most benefit from screening.

Other abnormalities of glucose metabolism, including pre-diabetes and metabolic syndrome, may also be associated

*Address correspondence to this author at the Nemazee Hospital, Nemazee Sq., Shiraz, Iran; Tel: +98 711 6474270; Fax: +98 7116474270 ;

E-mail:mm.montazeri@gmail.com with glaucoma risk, but few studies have examined this issue, with conflicting results [3-5]. There are conflicting results in different studies as to whether components of metabolic syndrome, including abdominal obesity, hypertension (HTN), elevated fasting blood glucose, and hyperlipidemia, may influence the risk of OAG.

Many Iranian people have multiple components of metabolic syndrome and studies on Iranian population showed that approximately $43 \%$ of Iranian met criteria for metabolic syndrome [6]. According to the prevalence of HTN, DM, hyperlipidemia, and obesity in Iranian population, it is important for eye care providers and ophthalmologists to establish a better conception of the association between metabolic syndrome and chronic eye diseases including OAG.

The aim of the present study was to determine the association between the clustered components of the metabolic syndrome and POAG. 


\section{MATERIALS AND METHODOLOGY}

\section{Study Design and Participants}

In this case-control study, we investigated a total of 200 Iranian subjects comprising 100 controls and 100 patients with POAG documented by clinical tests and examined by an experienced ophthalmologist, using standard ophthalmologic equipment.

The study was conducted according to the principles of the Helsinki Declaration and all participants gave their written informed consent.

POAG was defined by the criteria of the International Society of Geographic and Epidemiological Ophthalmology (ISGEO) [7]: an untreated Intraocular pressure (IOP) of 21 $\mathrm{mmHg}$ or more with a Goldman applanation tonometery, open anterior chamber angles on gonioscopy; glaucomatous optic disc changes (increased cup/disc ratio, thinning of the neuroretinal rim, notching) on ophthalmoscopy and visual field defects characteristic of glaucoma by standard automated perimetry with the Humphrey Visual Field Analyzer (HFA; Carl Zeiss Meditec Inc., Dublin, California). Patients included in the POAG group were shown not to have any systemic or local condition causing secondary glaucoma.

Central corneal thickness (CCT) was performed with ultrasonic pachymetry (Tomey Corporation, Nagoya, Japan).

Inclusion criteria for control subjects was IOP below 21 $\mathrm{mm} \mathrm{Hg}$, no glaucomatous changes in the optic disc, no visual field loss characteristic for glaucoma and no pseudoexfoliation material in the lens capsule or near the pupil.

The exclusion criteria were: angle closure glaucoma, high myopia ( $>5 \mathrm{D})$, nondilating pupil, patients unable to understand a visual analog pain scale chart, history of intraocular surgery, subluxated, traumatic, and complicated cataracts.

\section{Anthropometric and Blood Pressure Measurements}

Waist circumference (WC) was measured at the minimum circumference between the iliac crest and the rib cage over light clothing using a flexible measuring tape without any pressure to the body surface being recorded to the nearest $0.1 \mathrm{~cm}$. To avoid subjective error, all measurements were taken by the same male physician for all males and the same female physician for all females.

Height (by a stadiometer using a centimeter scale) and weight (by a clinical scale) were measured in light clothing and without shoes. Body mass index (BMI) was calculated by body weight $(\mathrm{kg}) /$ height $(\mathrm{m} 2)$ and $\mathrm{BMI} \geq 30 \mathrm{~kg} / \mathrm{m}^{2}$ defined as Obesity.

Blood pressure was measured twice after a 5 min rest from the right hand in a seated position using a standard mercury manometer by certified technicians, and the mean was recorded as blood pressure.

\section{Laboratory Measurements}

Blood samples were drawn after 10-12 hours of fasting through the antecubital vein. The samples were centrifuged within 30-45 min after collection. Fasting blood glucose (FBG), triglycerides (TG), total cholesterol (TC), low and high density lipoprotein cholesterol (LDL-C, HDL-C) were measured on fresh samples by standard kits (Pars Azmoun, Iran) by using auto-analyzer (Hitachi, Japan). FPG was measured by the enzymatic colorimetric method using glucose oxidize test. Serum TG concentrations were assayed using commercially available enzymatic reagents with glycerol phosphate oxidase. High-density lipoprotein cholesterol (HDL-C) was measured after precipitation of the apolipoprotein B-containing lipoproteins with phosphotungstic acid.

\section{Definition of Metabolic Syndrome}

Definition of MetS in this study was based on the National Cholesterol Education Program Adult Treatment Panel III (NCEP ATP III) criteria.

ATP III criteria (the presence of any three or more of the following five symptoms) [8]:

1- Abdominal obesity: waist circumference $>102 \mathrm{~cm}$ (men) and $>88 \mathrm{~cm}$ (women)

2- $\quad$ Hypertriglyceridemia: serum triglycerides level $\geq 150$ $\mathrm{mg} / \mathrm{dl}$ or drug treatment for elevated TG

3- Low HDL-cholesterol: $<40 \mathrm{mg} / \mathrm{dl}$ in men and $<50$ $\mathrm{mg} / \mathrm{dl}$ in women or drug treatment for low HDL-C

4- High blood pressure: SBP $\geq 130 \mathrm{mmHg}$ and/or $\mathrm{DBP} \geq 85 \mathrm{mmHg}$ or drug treatment for elevated blood pressure (high BP)

5- $\quad$ High fasting glucose (FBS): serum glucose level $\geq 110$ $\mathrm{mg} / \mathrm{dl}$ or on treatment for diabetes

\section{Statistical Analysis}

All data were analyzed by Statistical Package for Social Studies (SPSS) version 21 (SPSS Inc, Chicago, IL, USA). The continuous variables are reported as $M e a n \pm S D$ and categorical variables are presented as percentage. For the continuous variables, the data were tested for normality using the Kolmogorov-Smirnov test. Categorical variables were compared by chi-square test and the means were compared with student t-test. P-value $<0.05$ was considered statistically significant.

\section{RESULTS}

A total of 200 participants (100 in the glaucoma group and 100 in the control group) were included in our study. Table 1 shows a comparison of characteristics of the study participants with and without glaucoma. Mean age was $62.44 \pm 6.71$ years in the glaucoma group and 59.51 \pm 9.13 years in the control group $(\mathrm{P}=0.549)$. The glaucoma group comprised 34 men, while the control group included 42 $(\mathrm{P}=0.171)$. Lipid profile and FBS were not significantly different between two groups. There were significant differences in IOP and central corneal thickness, between the glaucoma and control groups (Table 1).

The prevalence of metabolic syndrome in the glaucoma group was $53 \%$ in comparison to $38 \%$ in the control group. 
Table 1. Comparing baseline characteristics of the study participants with and without the glaucoma.

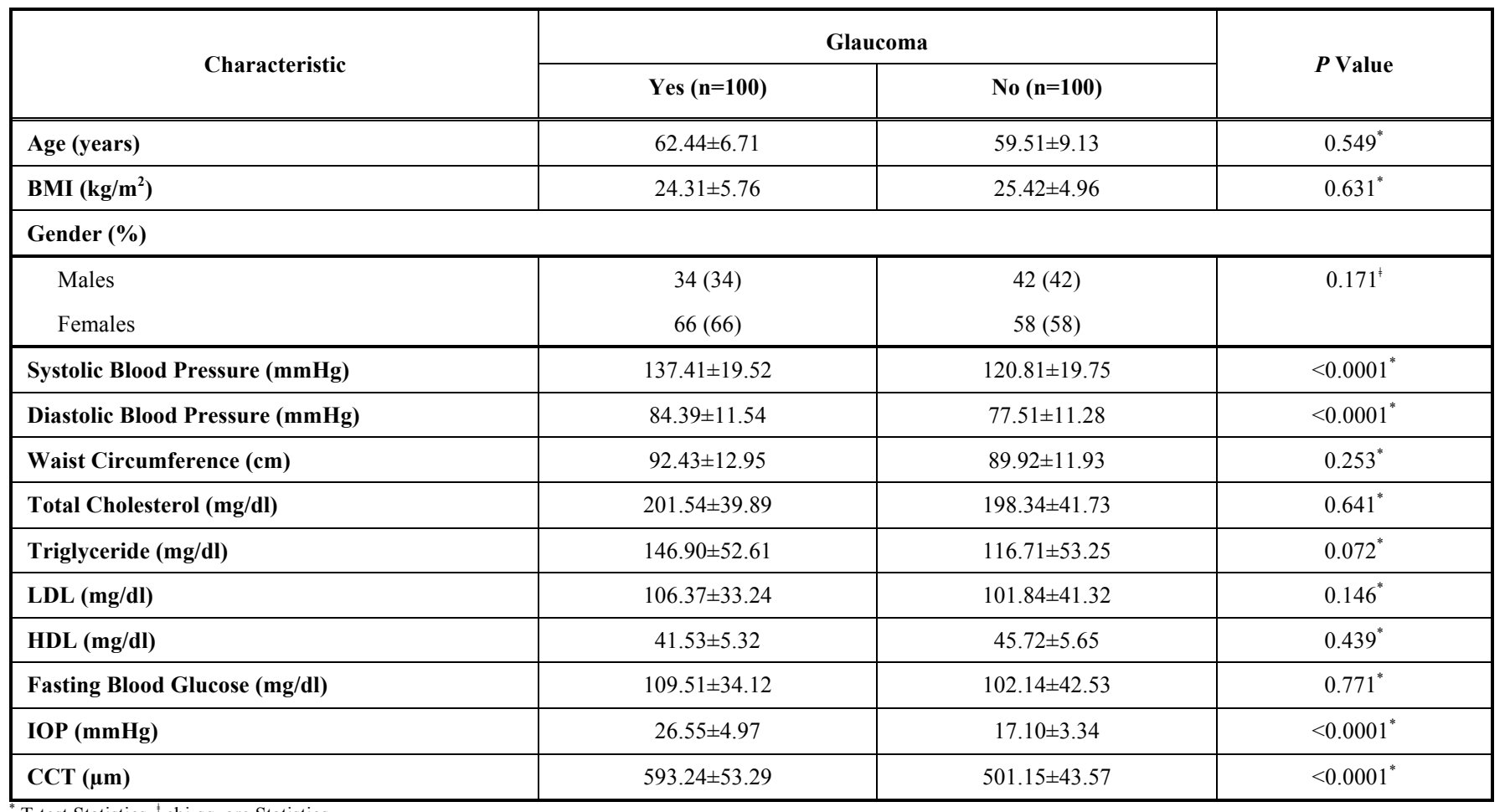

T-test Statistics, ${ }^{\prime}$ chi-square Statistics.

BMI, body mass index; LDL, low-density lipoprotein; HDL, high-density lipoprotein cholesterol; CCT, central corneal thickness.

The metabolic syndrome was significantly higher in patients with glaucoma $(p=0.037)$. MetS was associated with an increased odds ratio for an IOP higher than $21 \mathrm{mmHg}$ (OR: $1.72 ; 95 \%$ CI 1.03-2.79; $\mathrm{p}=0.034)$.

The mean IOP was $24.91 \pm 4.29 \mathrm{mmHg}$ in the patients without MetS, and $27.23 \pm 4.81 \mathrm{mmHg}$ in those with metabolic syndrome $(p=0.027)$. The subjects with metabolic syndrome had significantly higher IOP levels than those without metabolic syndrome. An analysis of the components of metabolic syndrome showed that the patients with elevated fasting glucose, high blood pressure and high triglycerides had significantly higher IOP levels, when compared to the subjects without these risk factors (Table 2). The mean values of CCT were $603.64 \pm 63.16 \mu \mathrm{m}$ in patients with metabolic syndrome and $579.27 \pm 72.87 \mu \mathrm{m}$ in the participant without metabolic syndrome $(\mathrm{p}=0.018)$. Patients with high blood pressure had significantly higher mean of CCT, when compared to the subjects without this risk factor. Other components of metabolic syndrome were found not to be associated with the mean of CCT (Table 2).

As shown in Table 3, elevated fasting glucose, high blood pressure and elevated triglyceride were associated with glaucoma. However, there was no association between abdominal obesity and low HDL with glaucoma.

Fig. (1) shows that only one percent of the glaucoma patients had no metabolic syndrome component, while 12 percent had all 5 components. The odds for glaucoma seem to vary for different components of MetS, and the risk estimate increased as the number of components of MetS increased from 1 to 5 . As shown in Table 4, individuals with 4 and 5 components of the MetS had an increased OR for glaucoma: 3.76 (95\% CI, 2.15-4.64) and 5.12 (95\% CI, 1.58-
8.39), respectively, compared with individuals with none of the components.

\section{DISCUSSION}

The prevalence of metabolic syndrome was significantly higher in patients with glaucoma in our study. MetS was associated with an increased odds ratio for an IOP higher than $21 \mathrm{mmHg}$. Also, the subjects with metabolic syndrome had significantly higher IOP levels than those without metabolic syndrome.

Few studies have evaluated the association between metabolic syndrome or glucose metabolism biomarkers and glaucoma, with conflicting results [3-5]. In the Singapore Malay Eye Study, participants with metabolic syndrome had a lower prevalence of glaucoma [3], while the number of metabolic syndrome components was positively associated with the hazard of open-angle glaucoma in a US cohort [5].

In our study, abdominal obesity was found not to be associated with the mean IOP in glaucoma patients. There was no association between abdominal obesity and glaucoma. Some prior reports revealed that abdominal obesity and increased BMI have already been related with higher IOP [9-12]. Several studies have reviewed the direct association between obesity and OAG; some studies have reported a relationship $[13,14]$ while the others have not [15-17] — which is consistent with our study.

Some hypotheses deal with the relationship between obesity and OAG. First, increased intraorbital fat tissue and increased blood viscosity result in episcleral venous pressure elevation. These factors could lead to a consequent decrease in outflow facility resulting in increased IOP. This theory is 
Table 2. Comparison of the mean values IOP and CCT according to each component of metabolic syndrome participants with glaucoma.

\begin{tabular}{|c|c|c|c|c|}
\hline Components & Mean IOP $( \pm$ SD) & P Value & Mean CCT $( \pm$ SD $)$ & P Value \\
\hline \multicolumn{5}{|c|}{ Abdominal Obesity } \\
\hline Yes & $26.23 \pm 4.17$ & 0.126 & $591.12 \pm 56.15$ & 0.317 \\
\hline No & $25.34 \pm 3.76$ & & $596.34 \pm 91.77$ & \\
\hline \multicolumn{5}{|c|}{ Elevated Fasting Glucose } \\
\hline Yes & $26.12 \pm 3.69$ & 0.033 & $584.59 \pm 76.28$ & 0.462 \\
\hline No & $24.59 \pm 2.45$ & & $597.72 \pm 92.65$ & \\
\hline \multicolumn{5}{|c|}{ High Blood Pressure } \\
\hline Yes & $27.24 \pm 2.62$ & $<0.0001$ & $601.38 \pm 74.67$ & 0.002 \\
\hline No & $23.83 \pm 4.47$ & & $576.23 \pm 93.79$ & \\
\hline \multicolumn{5}{|l|}{ Low HDL } \\
\hline Yes & $25.37 \pm 3.23$ & 0.234 & $585.53 \pm 97.28$ & 0.538 \\
\hline No & $26.29 \pm 2.72$ & & $598.09 \pm 64.92$ & \\
\hline \multicolumn{5}{|c|}{ Elevated Triglyceride } \\
\hline Yes & $27.51 \pm 2.39$ & 0.004 & $589.57 \pm 46.45$ & 0.317 \\
\hline No & $23.74 \pm 3.34$ & & $597.52 \pm 73.73$ & \\
\hline
\end{tabular}

Table 3. Associations of metabolic syndrome components with glaucoma.

\begin{tabular}{|c|c|c|c|}
\hline Components & OR & 95\% Confidence Interval & P Value \\
\hline \hline Abdominal Obesity & 1.12 & $0.72-2.01$ & 0.151 \\
\hline Elevated fasting glucose & 1.47 & $0.78-1.97$ & 0.031 \\
\hline Elevated blood pressure & 2.35 & $1.13-3.29$ & 0.006 \\
\hline Low HDL & 1.82 & $1.24-2.39$ & 0.312 \\
\hline Elevated triglyceride & 1.61 & $1.01-2.16$ & 0.047 \\
\hline
\end{tabular}

supported by some studies reporting that obesity is related to increase IOP $[9,10,12]$. Second, several studies showed that hyperleptinemia, a symptom of obesity, may result in increased oxidative stress [18]. It has been shown that trabecular meshwork of patients with OAG have higher levels of oxidative damage compared to healthy subjects [19, 20]. Third theory about the relationship between increased IOP and obesity suggests that when Goldmann tonometry is done at the slitlamp on obese patients, breath holding and thorax compression may result in transitory elevations in IOP in these patients [21].

In glaucoma patients in our study, high triglycerides had significantly higher IOP levels when compared to the subjects without elevated triglyceride. It was also shown that elevated triglycerides were associated with glaucoma. However, low HDL did not show a significant relationship with IOP and glaucoma.

Tan et al. [3] study found a small positive association between total cholesterol and triglyceride levels and IOP. Another population-based study found an association between cholesterol and IOP, whereas a study on patients with suspected glaucoma found them to have hypertriglyceridemia [22]. An association between hyperlipidemia with elevated IOP and OAG were reported in Oh et al. [23] and Jaen-Diaz et al. [24] studies, respectively. By treating hyperlipidemia, a reduction in the risk of developing OAG has been reported in some studies [25]. A proposed mechanism indicated that statins can increase aqueous outflow facility and it is reported that in an ischemia-reperfusion rat model of the retina, statins have neuroprotective effects [26].

In many studies, HTN was shown as an independent factor affecting IOP $[9,27,28]$. Same as in our findings, some studies demonstrate a relationship between HTN and OAG [27-29]. However, this relationship was not reported in other studies [15, 30-32].

To explain the association between HTN and OAG, there are numerous theories which have been suggested. First, hypertension may cause an increase in perfusion of the ciliary artery, leading to an increase in aqueous production, resulting in higher risk of developing OAG [33]. A second hypothesis suggests that patients with HTN may have arterial damage and stiffening of the small end-vessels feeding the optic nerve. These changes might predispose patients to 


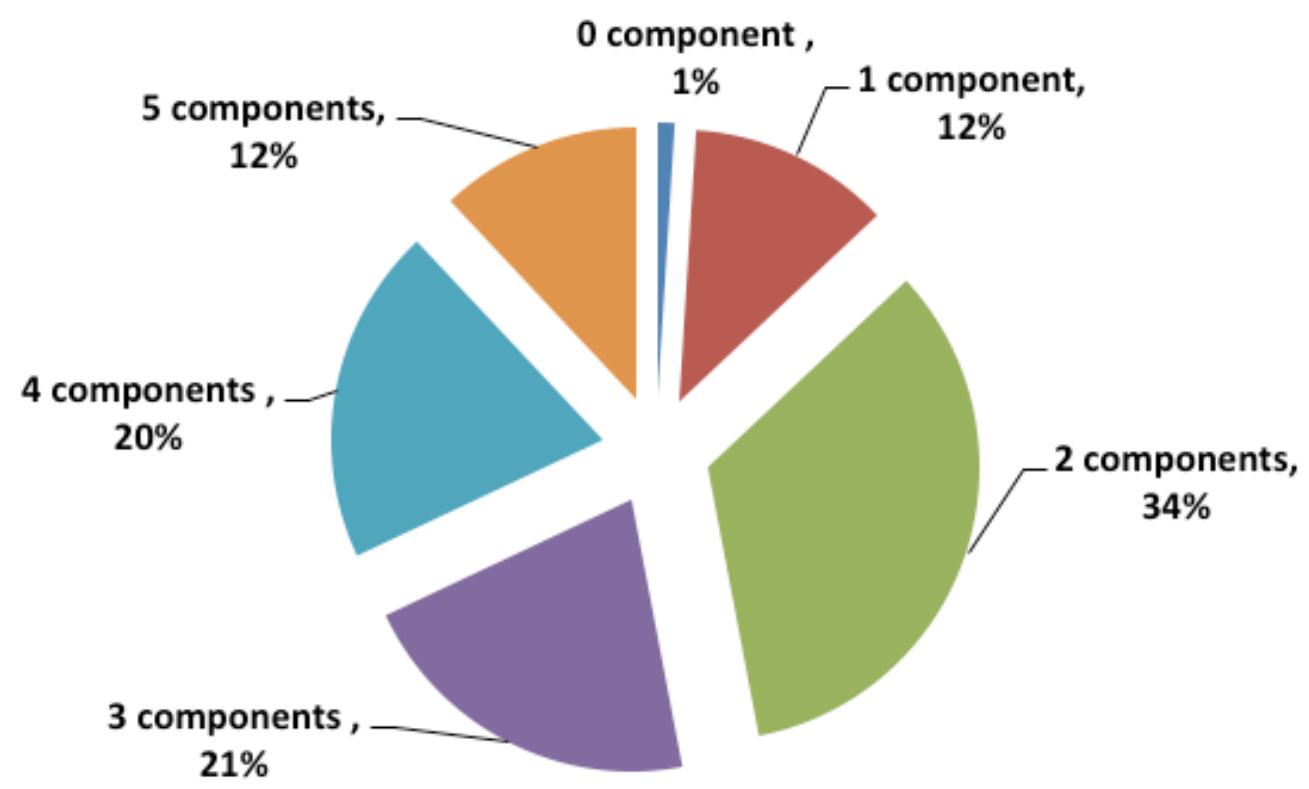

Fig. (1). Metabolic syndrome components frequency in patients with glaucoma.

developing glaucomatous optic neuropathy [34]. Another theory proposes that using anti-hypertensive medications may be accompanied with episodic systemic hypotension, resulting in decreased perfusion pressure which could damage the optic nerve [35].

Table 4. Multivariate odds ratio of glaucoma associated with several components of MetS.

\begin{tabular}{|c|c|c|c|}
\hline MetS Score & OR & $\mathbf{9 5 \%}$ Confidence Interval & P Value \\
\hline \hline 0 & 1 & & 1 \\
\hline 1 & 1.41 & $0.62-3.13$ & 0.729 \\
\hline 2 & 1.97 & $0.95-4.01$ & 0.162 \\
\hline 3 & 2.49 & $1.03-4.79$ & 0.236 \\
\hline 4 & 3.76 & $2.15-4.64$ & $<0.0001$ \\
\hline 5 & 5.12 & $1.58-8.39$ & $<0.0001$ \\
\hline
\end{tabular}

In the present study, an analysis of the components of metabolic syndrome showed that patients with elevated fasting glucose had significantly higher IOP levels compared to subjects with normal FBS. Also, elevated fasting glucose was associated with glaucoma.

The potential mechanisms underlying the association between glucose metabolism abnormalities and the prevalence of glaucoma in subjects without diabetes are unclear. The presence of the metabolic syndrome and elevated levels of glucose, HOMA-IR and glycosylated hemoglobin may be associated with increased levels of IOP, a key causal factor for glaucoma [16, 23]. Hyperglycemia increased fibronectin production in the bovine trabecular meshwork, which may increase the resistance to aqueous humor outflow and lead to elevated IOP [36]. Moreover, hyperglycemia could induce apoptosis in retinal neuronal cells through the hexosamine biosynthetic pathway [37]. Additionally, hyperglycemia-induced oxidative stress and advanced glycation end products may increase apoptotic death in retinal neurons [38, 39].

It has been shown in studies that DM is associated with POAG. There have been some theories that could explain the link between DM and POAG. First, there is evidence that shows that the risk of neuronal injury from stress may increase with the presence of long-standing elevated blood glucose alongside dyslipidemia [40]. Laboratory measurements have provided strong evidence for this relationship [41]. Secondly, reports indicated that the capacity to auto-regulate blood flow may decrease in diabetic eyes and so retinal blood flow will reduce in these eyes. Consequently, in response to elevated IOP, relative hypoxia occurres in diabetic eyes and levels of hypoxiainducible factor-1 (HIF-1 $\alpha$ ) increase in retinal ganglion cells, and in the optic nerve head of human glaucomatous eyes [42].

The next theory may be related to the remodeling of the connective tissue of the optic nerve head. Studies show that DM may exacerbate connective tissue remodeling. This remodeling may decrease compliance at the trabecular meshwork resulting in an increased IOP and also in decreased compliance of the lamina cribrosa causing higher mechanical stress on the optic nerve head. Genetic factors and diabetes-related autonomic dysfunction probably contribute to this relationship [43].

\section{CONCLUSION}

Glaucoma has a long latency period, in which glaucomatous optic nerve damage is ongoing but remains asymptomatic until later stages. The adherence to regular ophthalmological exams should be emphasized in patients with MetS, especially among those with 4 or 5 components of MetS.

Our data show an increased prevalence of components of metabolic syndrome in patients with glaucoma. Given that approximately half of the Iranian population has metabolic 
syndrome, the prevalence of $\mathrm{OAG}$ might increase in the coming years. The mechanisms underlying these associations need to be established in future studies. Our results support the recommendation that patients with metabolic syndrome should undergo regular ophthalmological exams to monitor the onset or progression of glaucoma. Further research may aid understanding of the complex interactions between metabolic abnormalities, IOP, and the risk and pathogenesis of glaucoma.

\section{ABBREVIATIONS}

\begin{tabular}{|c|c|c|}
\hline BMI & $=$ & Body mass index \\
\hline $\mathrm{CCT}$ & $=$ & Central corneal thickness \\
\hline FBG & $=$ & Fasting blood glucose \\
\hline HDL & $=$ & high density lipoprotein cholesterol \\
\hline IAPB & $=$ & $\begin{array}{l}\text { International Agency for the Prevention } \\
\text { of Blindness }\end{array}$ \\
\hline IOP & $=$ & Intraocular pressure \\
\hline ISGEO & $=$ & $\begin{array}{l}\text { International Society of Geographic and } \\
\text { Epidemiological Ophthalmology }\end{array}$ \\
\hline LDL & $=$ & low density lipoprotein cholesterol \\
\hline NCEP ATP III & $=$ & $\begin{array}{l}\text { National Cholesterol Education Program } \\
\text { Adult Treatment Panel III }\end{array}$ \\
\hline POAG & $=$ & Primary open-angle glaucoma \\
\hline SPSS & $=$ & Statistical Package for Social Studies \\
\hline WC & $=$ & Waist circumference \\
\hline WHO & $=$ & World Health Organization \\
\hline
\end{tabular}

\section{CONFLICT OF INTEREST}

The authors confirm that this article content has no conflict of interest.

\section{ACKNOWLEDGEMENTS}

Declared none.

\section{REFERENCES}

[1] Coleman AL, Brigatti L. The glaucomas. Minerva Med 2001; 92(5): 365-79.

[2] Klauss V, Schaller UC. International initiatives for the prevention of blindness. Ophthalmologe 2007; 104(10): 855-9.

[3] Tan GS, Wong TY, Fong CW, Aung T. Diabetes, metabolic abnormalities, and glaucoma. Arch Ophthalmol 2009; 127(10): 1354-61

[4] Elisaf M, Kitsos G, Bairaktari E, Kalaitzidis R, Kalogeropoulos C, Psilas K. Metabolic abnormalities in patients with primary openangle glaucoma. Acta Ophthalmol Scand 2001; 79(2): 129-32.

[5] Newman-Casey PA, Talwar N, Nan B, Musch DC, Stein JD. The relationship between components of metabolic syndrome and openangle glaucoma. Ophthalmology 2011; 118(7): 1318-26.

[6] Maleki A, Rashidi N, Aghaei Meybodi H, et al. Metabolic syndrome and inflammatory biomarkers in adults: a populationbased survey in western region of Iran. Int Cardiovasc Res J 2014; 8(4): 156-60.

[7] Foster PJ, Buhrmann R, Quigley HA, Johnson GJ. The definition and classification of glaucoma in prevalence surveys. $\mathrm{Br} \mathrm{J}$ Ophthalmol 2002; 86(2): 238-42.
[8] Maleki A, Montazeri M, Rashidi N, Montazeri M, YousefiAbdolmaleki E. Metabolic syndrome and its components associated with chronic kidney disease. J Res Med Sci 2015; 20(5): 465-9.

[9] Wu SY, Leske MC. Associations with intraocular pressure in the barbados eye study. Arch Ophthalmol 1997; 115(12): 1572-6.

[10] Lee JS, Lee SH, Oum BS, Chung JS, Cho BM, Hong JW. Relationship between intraocular pressure and systemic health parameters in a Korean population. Clin Exp Ophthalmol 2002; 30(4): 237-41.

[11] Cheung N, Wong TY. Obesity and eye diseases. Surv Ophthalmol 2007; 52(2): 180-95.

[12] Mori K, Ando F, Nomura H, Sato Y, Shimokata H. Relationship between intraocular pressure and obesity in Japan. Int J Epidemiol 2000; 29(4): 661-6.

[13] Kaimbo DK, Buntinx F, Missotten L. Risk factors for open-angle glaucoma: a case-control study. J Clin Epidemiol 2001; 54(2): 16671 .

[14] Zang EA, Wynder EL. The association between body mass index and the relative frequencies of diseases in a sample of hospitalized patients. Nutr Cancer 1994; 21(3): 247-61.

[15] Leske MC, Connell AM, Wu SY, Hyman LG, Schachat AP. Risk factors for open-angle glaucoma. the barbados eye study. Arch Ophthalmol 1995; 113(7): 918-24.

[16] Pasquale LR, Kang JH, Manson JE, Willett WC, Rosner BA, Hankinson SE. Prospective study of type 2 diabetes mellitus and risk of primary open-angle glaucoma in women. Ophthalmology 2006; 113(7): 1081-6.

[17] Gasser P, Stumpfig D, Schotzau A, Ackermann-Liebrich U, Flammer J. Body mass index in glaucoma. J Glaucoma 1999; 8(1): 8-11.

[18] Bouloumie A, Marumo T, Lafontan M, Busse R. Leptin induces oxidative stress in human endothelial cells. FASEB J 1999; 13(10): 1231-8.

[19] Izzotti A, Sacca SC, Cartiglia C, De Flora S. Oxidative deoxyribonucleic acid damage in the eyes of glaucoma patients. Am J Med 2003; 114(8): 638-46.

[20] Sacca SC, Pascotto A, Camicione P, Capris P, Izzotti A. Oxidative DNA damage in the human trabecular meshwork: clinical correlation in patients with primary open-angle glaucoma. Arch Ophthalmol 2005; 123(4): 458-63.

[21] dos Santos MG, Makk S, Berghold A, Eckhardt M, Haas A. Intraocular pressure difference in Goldmann applanation tonometry versus Perkins hand-held applanation tonometry in overweight patients. Ophthalmology 1998; 105(12): 2260-3.

[22] Chisholm IA, Stead S. Plasma lipid patterns in patients with suspected glaucoma. Can J Ophthalmol 1988; 23(4): 164-7.

[23] Oh SW, Lee S, Park C, Kim DJ. Elevated intraocular pressure is associated with insulin resistance and metabolic syndrome. Diabetes Metab Res Rev 2005; 21(5): 434-40.

[24] Diaz JJ, Alcolea SI, De Castro LF, Martinez PT, Campos OP, Morales CR. Glaucoma and ocular hypertension in primary care. Aten Primaria 2001; 28(1): 23-30.

[25] McGwin G, Jr., McNeal S, Owsley C, Girkin C, Epstein D, Lee PP. Statins and other cholesterol-lowering medications and the presence of glaucoma. Arch Ophthalmol 2004; 122(6): 822-6.

[26] Honjo M, Tanihara H, Nishijima K, et al. Statin inhibits leukocyteendothelial interaction and prevents neuronal death induced by ischemia-reperfusion injury in the rat retina. Arch Ophthalmol 2002; 120(12): 1707-13.

[27] Bonomi L, Marchini G, Marraffa M, Bernardi P, Morbio R, Varotto A. Vascular risk factors for primary open angle glaucoma: the Egna-Neumarkt Study. Ophthalmology 2000; 107(7): 1287-93.

[28] Dielemans I, Vingerling JR, Algra D, Hofman A, Grobbee DE, de Jong PT. Primary open-angle glaucoma, intraocular pressure, and systemic blood pressure in the general elderly population: the rotterdam study. Ophthalmology 1995; 102(1): 54-60.

[29] Perez ZJJ, Perez VMP, Jordana CM, De Imperial MJ. Intraocular pressure and prevalence of occult glaucoma in a village of Murcia. Arch Soc Esp Oftalmol 2000; 75(3): 171-8.

[30] Quigley HA, West SK, Rodriguez J, Munoz B, Klein R, Snyder R. The prevalence of glaucoma in a population-based study of Hispanic subjects: Proyecto VER. Arch Ophthalmol 2001; 119(12): 1819-26.

[31] Wormald RP, Basauri E, Wright LA, Evans JR. The African Caribbean eye survey: risk factors for glaucoma in a sample of 
African Caribbean people living in London. Eye (Lond) 1994; 8( Pt 3): 315-20.

[32] Kaimbo Wa Kaimbo D, Missotten L. Risk factors for open-angle glaucoma in 260 black subjects in Congo. Bull Soc Belge Ophtalmol 1997; 267: 29-34.

[33] Shiose Y, Kawase Y. A new approach to stratified normal intraocular pressure in a general population. Am J Ophthalmol 1986; 101(6): 714-21.

[34] Wolf S, Arend O, Sponsel WE, Schulte K, Cantor LB, Reim M. Retinal hemodynamics using scanning laser ophthalmoscopy and hemorheology in chronic open-angle glaucoma. Ophthalmology 1993; 100(10): 1561-6.

[35] Pache M. Primary open-angle glaucoma and systemic diseases. Ophthalmology 2007; 104(5): 431-41; quiz 42-3.

[36] Sato T, Roy S. Effect of high glucose on fibronectin expression and cell proliferation in trabecular meshwork cells. Invest Ophthalmol Vis Sci 2002; 43(1): 170-5.

[37] Nakamura M, Barber AJ, Antonetti DA, et al. Excessive hexosamines block the neuroprotective effect of insulin and induce apoptosis in retinal neurons. J Biol Chem 2001; 276(47): 43748-55.
[38] van Dam PS. Oxidative stress and diabetic neuropathy: pathophysiological mechanisms and treatment perspectives. Diabetes Metab Res Rev 2002; 18(3): 176-84.

[39] King GL, Brownlee M. The cellular and molecular mechanisms of diabetic complications. Endocrinol Metab Clin North Am 1996; 25(2): 255-70.

[40] Kong GY, Van Bergen NJ, Trounce IA, Crowston JG. Mitochondrial dysfunction and glaucoma. J Glaucoma 2009; 18(2): 93-100.

[41] Toda N, Nakanishi-Toda M. Nitric oxide: ocular blood flow, glaucoma, and diabetic retinopathy. Prog Retin Eye Res 2007; 26(3): 205-38.

[42] Arjamaa O, Nikinmaa M. Oxygen-dependent diseases in the retina: role of hypoxia-inducible factors. Exp Eye Res 2006; 83(3): 47383.

[43] Roberts MD, Grau V, Grimm J, et al. Remodeling of the connective tissue microarchitecture of the lamina cribrosa in early experimental glaucoma. Invest Ophthalmol Vis Sci 2009; 50(2): $681-90$.

(C) Rasoulinejad et al.; Licensee Bentham Open.

This is an open access article licensed under the terms of the (https:/creativecommons.org/licenses/by/4.0/legalcode), which permits unrestricted, noncommercial use, distribution and reproduction in any medium, provided the work is properly cited. 